\title{
Relato de experiência da vivência de residentes de enfermagem frente a pandemia COVID-19
}

\author{
Experience report of the experience of nursing residents in front of the pandemic COVID-19 \\ Informe de experiencia de la experiencia de enfermeros residentes frente a la pandemia COVID-19
}

\begin{abstract}
RESUMO
Objetivo: descrever a vivência de residentes de enfermagem de um Hospital Federal da zona norte da cidade do Rio de Janeiro durante a pandemia do novo coronavírus. Método: trata se de um relato de experiência descritivo com abordagem qualitativa, a partir de vivências de residentes de enfermagem no primeiro ano do curso de pós-graduação em nível de especialização, nos moldes de residência. Resultado: A experiência caracteriza-se com os fluxos operacionais e ambiência física desenvolvidos pela Instituição, a utilização de equipamentos de proteção individual e os desafios vivenciados neste período de pandemia. Conclusão: O SARS CoV - 2 foi descoberto recentemente, os estudos sobre o vírus ainda não é o suficiente para a elaboração de protocolos permanentes, as mudanças são constantes. Os profissionais de saúde são vulneráveis já que o número de mortos aumentou. No entanto é de relevância a atualização técnico científica, assim como resolução da inquietude dos profissionais de saúde.
\end{abstract}

DESCRITORES: Profissionais de saúde; Enfermagem; Infecções por coronavírus; Pandemia.

\section{ABSTRACT}

Objective: to describe the experience of nursing residents at a Federal Hospital in the north of the city of Rio de Janeiro during a new coronavirus pandemic. Method: this is a descriptive experience report with a qualitative approach, based on the experiences of nursing residents in the first year of the postgraduate course at a specialization level, along the lines of residency. Result: The experience stands out with the operational flows and physical environment developed by the Institution, the use of personal protective equipment and the challenges experienced in this pandemic period. Conclusion: SARS CoV - 2 was recently discovered, studies on the virus are still not enough for the elaboration of permanent protocols, as the changes are constant. Health professionals are vulnerable since the number of people increased. However, it is necessary to produce a scientific technical update, as well as to resolve the concern of health professionals.

DESCRIPTORS: Health professionals; Nursing; Coronavirus infections; Pandemic.

\section{RESUMEN}

Objetivo: describir la experiencia de los residentes de enfermería de un Hospital Federal del norte de la ciudad de Río de Janeiro durante una nueva pandemia de coronavirus. Método: se trata de un relato de experiencia descriptiva con enfoque cualitativo, basado en las vivencias de residentes de enfermería en el primer año del posgrado a nivel de especialización, en la línea de la residencia. Resultado: Se destaca la experiencia con los flujos operacionales y ambiente físico desarrollado por la Institución, el uso de equipos de protección personal y los desafíos vividos en este período pandémico. Conclusión: El SARS CoV - 2 fue descubierto recientemente, los estudios sobre el virus aún no son suficientes para la elaboración de protocolos permanentes, ya que los cambios son constantes. Los profesionales de la salud son vulnerables ya que aumentó el número de personas. Sin embargo, es necesario producir una actualización científico-técnica, así como resolver la inquietud de los profesionales de la salud.

DESCRIPTORES: Profesionales de la salud; Enfermería; Infecciones por coronavirus; Pandemia.

RECEBIDO EM: 18/09/2020 APROVADO EM: 30/09/2020

\section{Dayane Martins da Silva Campos}

Enfermeira Residente. Universidade Federal do Estado do Rio de Janeiro (UNIRIO). Enfermeira.

ORCID: 0000-0002-0193-4417 


\section{Eva Natalina Ferreira Costa}

Enfermeira Residente. Universidade Federal do Estado do Rio de Janeiro (UNIRIO). Enfermeira. ORCID: 0000-0003-2673-6967

\section{Flavia Martins Branco}

Enfermeira Residente. Universidade Federal do Estado do Rio de Janeiro (UNIRIO). Enfermeira. ORCID: 0000-0003-3484-8555

\section{INTRODUÇÃO}

0 curso de pós-graduação em nível de especialização, sob a forma de treinamento em serviço para Enfermeiro, nos moldes de residência visa um preparo com base científica, viabilizando aos enfermeiros uma competência técnica e julgamento clínico.

Em janeiro de 2020 no Brasil foi acionado o Centro de Operações de Emergência (COE) em Saúde Pública para o novo coranavírus (Covid 19). A vigilância epidemiológica de infecção humana pelo SARS CoV -2 será construída e consolidada pela Organização Mundial de Saúde (OMS) com informações fornecidas dos países com novas evidências técnicas e científicas publicadas ${ }^{1}$.

Desde então começou a propagação do mais novo patógeno espalhado pelo mundo causando uma nova doença que representa uma grande ameaça para população mundial. Suspendendo as atividades diárias da população, relacionando a necessidade de manter o distanciamento social solicitado pela Organização Mundial de Saúde (OMS), com o objetivo de diminuir a propagação da doença².

O SARS CoV - 2 é um vírus envelopado de ácido ribonucleico (RNA), encontrados habitualmente em seres humanos, outros mamíferos e aves, sendo capaz de provocar doenças entéricas, respiratórias, hepáticas e neurológicas. Refere se de um vírus de disseminação maior que os outros da mesma espécie, mesmo possuindo letalidade em torno de $3 \%^{3}$.

A doença é caracterizada no seu quadro clínico inicial como síndrome gripal, mas casos leves iniciais podem evoluir para um aumento progressivo da temperatura e a febre pode persistir de 3-4 dias, diferente do descenso observa- do nos casos de influenza. O diagnóstico e realizado através da investigação clínico epidemiológica e do exame físico. Apesar da maioria dos casos de a doença ser considerados leves, alguns indivíduos desenvolverão doenças graves que $14 \%$ vão precisar de oxigenoterapia, e aproximadamente $5 \%$ necessitarão de ventilação mecânica. $O$ diagnóstico mais comum em pacientes graves é a pneumonia ${ }^{4}$.

O primeiro caso de covid 19 aqui no Brasil foi confirmado no dia 26 de fevereiro de 2020. Morador da cidade de São Paulo e havia chegado de uma viagem na Itália dias antes do seu diagnóstico. Poucos dias, depois do primeiro caso outras pessoas foram diagnosticadas com a infecção viral. Apontando a velocidade de disseminação da doença ${ }^{5}$.

No dia 05 de março de 2020 foi registrado o primeiro caso de covid -19 na cidade do Rio de Janeiro, informado pela Secretaria Estadual de Saúde a um meio de comunicação (jornal Uol). Este paciente chegou de viagem de um país com o nome não mencionado. No dia 12 de março em entrevista o Secretário Estadual de Saúde Edmar Santos confirma o segundo caso confirmado através de uma transmissão local ${ }^{6}$.

A Organização Mundial de Saúde (OMS) declarou estado de emergência em saúde pública de relevância internacional semanas depois da confirmação do primeiro caso de coronavírus no mundo ${ }^{7}$.

O tempo médio de incubação do SARS CoV -2 nos seres humanos é estimado de 5 a 6 dias, com intervalos que podem variar de 0 a 14 dias. (Ministério da saúde 2020). A preocupação neste momento é a alta capacidade de transmissão do vírus, pois o número de indivíduo infectado pode crescer rapi- damente dentro de poucos dias 8 .

Mediante o canário mundial o Ministério da Saúde regulamenta a portaria ${ }^{\circ}$ 356 de 11 de março de 2020. Medidas passaram a ser adotadas. No intuito de reduzir a disseminação do vírus (SAÚDE, 2020) .

Em face ao exposto o estudo tem como objetivo descrever a vivência de residentes de enfermagem de um Hospital Federal da zona norte da cidade do Rio de Janeiro durante a pandemia do novo vírus SARS CoV-2.

\section{MÉTODO}

Trata se de um relato de experiência descritivo com abordagem qualitativa, a partir de vivências do primeiro ano do curso de pós-graduação em nível de especialização, sob a forma de treinamento em serviço para Enfermeiro nos moldes de residência, sobre a experiência da assistência prestada aos pacientes confirmados ou suspeitos do novo coranavírus em um Hospital Federal da zona Oeste da cidade do Rio de Janeiro. A Instituição conta com o total de 100 leitos, sendo 7 destinados a emergência e 13 leitos Unidade de Terapia Intensiva. O Hospital atende somente pacientes do Sistema Único de Saúde e não é referência para o tratamento do novo coronavírus.

A busca de artigos foi realizada no banco de dados da biblioteca virtual em saúde (BVS), e na base de dados de Latino - Americana e do Caribe em ciência de saúde (LILACS), nas bases de dados PUBMED e Scielo, utilizando os seguintes descritores: Profissionais de saúde; Enfermagem; Infecções por coronavírus; Pandemia. Como critérios de inclusão foram selecionados artigos originais em português e inglês no espaço 
temporal de 2019 a 2020 e que atendia questão norteadora. Foram excluídos relatos de casos, artigos revisão de literatura e artigos fora do tempo estipulado.

O levantamento é fundamentado na experiência de residentes de enfermagem no ápice da pandemia. Em relação ao tempo, foi realizado no período de março a julho de 2020.

\section{Relato de experiência}

Iniciamos a residência no dia 02 de Março, onde muitas de nós, não imaginávamos o que estava por vir, antes mesmo de ser registrado o primeiro caso no hospital, já havia uma equipe de enfermeiros fazendo treinamentos sobre o uso adequado dos equipamentos de proteção individual, etiologia da doença, manejo dos pacientes diagnosticados e suspeitos do coronavírus. No dia 11 de março a Organização Mundial de saúde (OMS) declarada Pandemia. O medo e ansiedade só aumentava sabendo que o vírus estava cada vez mais próximo.

Contudo, mesmo diante de todas as medidas preventivas foi registrado o primeiro caso confirmado através do exame Transcrição reversa seguida de reação em cadeia da polimerase (RT-PCR) no dia 13 de março de 2020. A paciente procurou a unidade de saúde para tratamento oncológico. Após 5 dias de internação manifestou os sintomas, foi coletado o exame o qual o resultado foi positivo para covid- 19.

O tempo foi passando e o número de casos foram aumentando. A cada momento chegava uma nova informação, os protocolos tinham mudanças constantes. O medo do desconhecido foi uma aflição naquele momento, passamos a estudar, procurar artigos, notícias, fatos que nos mostrasse a gravidade do novo e assustador cenário vividos desde então. Foram realizados treinamentos sobre a correta higienização das mãos, como se paramentar e desparamentar sem se contaminar, os EPI 'S que devemos usar por horas, que por vezes causavam lesões em nossa pele, porém essenciais no atendimento desses pacientes.
Em contrapartida

frente ao impacto

emocional

vivenciado pelas

residentes e equipes

de enfermagem,

neste momento

de pandemia, é

necessário que sejam

ofertadas medidas

de segurança

satisfatórias para

estes profissionais.

Visando a

diminuição da

insegurança, medo

e ansiedade. Com

finalidade de

reduzir a sobrecarga

emocional neste

momento desafiador.
Em contrapartida frente ao impacto emocional vivenciado pelas residentes e equipes de enfermagem, neste momento de pandemia, é necessário que sejam ofertadas medidas de segurança satisfatórias para estes profissionais. Visando a diminuição da insegurança, medo e ansiedade. Com finalidade de reduzir a sobrecarga emocional neste momento desafiador.

\section{DISCUSSÃO}

No entanto as mudanças radicais experienciadas pelos profissionais de saúde neste momento de pandemia, pode causar situações psicológicas graves. Além do medo de morrer, a pandemia do covid-19 pode trazer implicações para outras esferas, como fechamento de escola, gestão empresarial, organização familiar, locais públicos, mudanças nas rotinas de trabalho, isolamento e distanciamento social. Além disso o momento econômico tem gerado grande insegurança provocando sentimento de desamparo e abandono ${ }^{10}$.

Segundo o novo Jornal Inglês de Medicina, de acordo com as experiências com o SARS CoV é esperado que a transmissão do novo vírus aconteça em menor intensidade por meio de aerossóis e fômites, e com maior através de gotículas, sendo assim a importância da realização de medidas de saúde pública incluindo a quarentena, diagnóstico, adesão criteriosa ás precauçôes universais nos ambientes de saúde para diminuir a transmissão do covid $-19^{11}$.

Portanto, diz Victor Grabois, proteger profissionais de saúde é oferecer condições adequadas para trabalhar, como disponibilizar equipamentos de proteção individual em quantidade e qualidade suficientes e capacitá-los para o seu uso adequado, oferecer segurança psicológica aos trabalhadores da saúde. Respondendo suas preocupações, dúvidas, medos, facilitar ao máximo o processo de higienização das mãos. Profissionais protegidos e seguros são pré-requisito para a saúde dos trabalhadores da saúde ${ }^{12}$. 
A Organização Mundial de Saúde (OMS) publicou recentemente um guia de orientações para os cuidados da saúde mental dos profissionais de saúde e profissionais envolvidos nos serviços hospitalares. Alertando aos lideres sobre os impactos emocionais causados pela pandemia covid -19. A sobrecarga de tratabalho, estresse, insegurança ocasiona transtornos a saúde mental ${ }^{13}$.

O Conselho Federal de Enfermagem (COFEN) também disponibilizou no hotsite um programa Juntos Contra o Coronavírus com atendimentos 24 horas para os profissionais de enfermagem. $\mathrm{O}$ atendimento começou no dia 26 de março de 2020, a equipe é formada por enfermeiros voluntários especializados na assistência de saúde mental, que visam contribuir com os milhares de profissionais que têm trabalhado incansavelmente nas unidades de saúde do país ${ }^{14}$.

\section{Restruturação de ambiência e fluxo}

O hospital tem emergência de porta aberta. Foi elaborado um fluxo somente para pacientes com covid-19 ou suspeitos dentro da emergência, pois continuam recebendo outros casos na emergência. O hospital é certificado para o uso da escala de Manchester, utilizada para classificação de risco. Um paciente com síndrome gripal leve, pela classificação de Manchester leva em torno de 2 horas e 40 minutos para ser atendido. Se deixasse esse paciente junto com os outros, ele estaria tossindo, espirrando e disseminando o vírus que poderia infectar os outros pacientes que aguardam atendimento. Foi elaborado e aplicado o fluxo de triagem rápida (fast track). É realizado uma triagem rápida do paciente para determinar se é uma síndrome gripal leve, se tem ou não critérios de gravidade. Se for síndrome gripal leve o paciente é atendido e encaminhado para casa com receita, atestado e orientações para isolamento domiciliar. Se for caracterizado síndrome gripal grave ou o paciente apresentar/ relatar alguma comorbidade ele é encaminhado
A Instituição

oferece atendimento

psicológico no

contexto hospitalar

para os profissionais

de saúde incluindo

residentes. Durante

a pandemia está rede

foi ampliada, este

apoio psicológico é

fundamental, e de

extrema importância,

pois enfrentamos

situações diversas

que são geradoras

de estresse, como

a dor, sofrimento,

impotência e

angústia, onde há um

desgaste emocional

muito grande. para emergência para um atendimento especializado.

$\mathrm{Na}$ Clínica Médica, foram adequadas medidas na infraestrutura, foi separado uma parte da enfermaria do setor para receber casos suspeitos e confirmados da Covid-19, foi preparado uma sala para paramentação e desparamentação, e outra para diluir medicações e guardar material. Foram realizados treinamentos sobre a correta higienização das mãos.

A unidade clínica cirúrgica que atende pacientes adultos com diferentes diagnósticos, em um curto espaço de tempo passou por adequações em seu espaço físico para atender os novos casos de covid-19, a implementação do serviço também foi readequada para garantir equidade aos usuários do serviço de saúde. Conforme ocorreu em outros países a contaminação dos profissionais de saúde foi em grande quantidade, tornando o dimensionamento inadequado dos profissionais em cada plantão. Nesse período conseguimos designar um planejamento prévio para as diligências de urgência no setor mesmo com as sobrecargas das funções, eludir a contaminação cruzada e a própria contaminação antes, durante e após da carga horário de trabalho, um serviço de preocupação constante.

A Instituição oferece atendimento psicológico no contexto hospitalar para os profissionais de saúde incluindo residentes. Durante a pandemia está rede foi ampliada, este apoio psicológico é fundamental, e de extrema importância, pois enfrentamos situações diversas que são geradoras de estresse, como a dor, sofrimento, impotência e angústia, onde há um desgaste emocional muito grande.

\section{CONCLUSÃO}

O SARS CoV - 2 foi descoberto recentemente, os estudos sobre o vírus ainda não é o suficiente para a elaboração de protocolos permanentes, as mudanças ainda são constantes. Os profissionais de saúde são vulneráveis já que o número de mortos aumentou bastante. Muitos sentimentos e sensações como 
exaustão, sobrecarga de trabalho. Em vista disso é de relevância a atualização técnico científica assim como resolução da inquietude e desafios dos profissionais de saúde, dado que parte da solução deste cenário precisa disso.

Uma das particularidades da doença, que atinge a população do grupo de risco e os profissionais de saúde, é a capacidade de contágio e as possíveis complicações no organismo infectado. Por isso, é importante que esses profissionais conheçam os protocolos de uso dos equipamentos de proteção individual. Pois se utilizados adequadamente os profissionais trabalharam com mais segurança.

Portanto, a reflexão proposta por este relato de experiência é que apesar dos momentos vivenciados nesta Instituição, vale ressaltar que foram os profissionais de enfermagem os mais expostos, cabendo à Instituição de saúde a garantia da estrutura adequada e os meios necessários para o manejo dos casos, assegurando uma atuação livre de riscos à sociedade.

\section{REFERÊNCIAS}

1. Rizzotto Maria Lúcia Frizon. As políticas de saúde e a humanização da assistência. Rev. bras. enferm. [Internet]. 2002 Feb [cited 2020 Oct 15] ; 55( 2 ): 196-199.

2. Benevides Regina, Passos Eduardo. A humanização como dimensão pública das políticas de saúde. Ciênc. saúde coletiva [Internet]. 2005 Sep [cited 2020 Oct 15] ; 10 ( 3 ): 561-571.

3. Brasil. Ministério da Saúde. Programa Nacional de Humanização da Assistência Hospitalar. Brasília, 2001. Disponivel em: http://bvsms.saude.gov.br/bvs/publicacoes/pnhah01.pdf

4. Brasil. Ministério da Saúde. HumanizaSUS: política nacional de humanização. Brasília, 2003. Disponível em: http://portal.saude. gov.br/portal/arquivos/pdf/doc_base.pdf

5. Silveira Camila Santejo, Zago Márcia Maria Fontão. Pesquisa brasileira em enfermagem oncológica: uma revisão integrativa. Rev latinoam enferm. 2006; 14(4): 614-619.

6. Polit Denise F., Beck Cheryl Tatano. Fundamentos da pesquisa em enfermagem: avaliação de evidências para a prática em enfermagem. $7^{\text {a }}$ ed. Porto Alegre: Artmed; 2011.

7. Mendes Karina Dal Sasso, Silveira Renata Cristina de Campos Pereira, Galvão Cristina Maria. Revisão integrativa: método de pesquisa para a incorporação de evidências na saúde e na enfermagem. Texto contexto - enferm. [Internet]. 2008 Dec [cited 2020 Oct 15]; 17(4): 758-764.

8. Barbosa Guilherme Correa, Meneguim Silmara, Lima Silvana Andréa Molina, Moreno Vania. Política Nacional de Humanização e formação dos profissionais de saúde: revisão integrativa. Rev. bras. enferm. [Internet]. 2013 Feb [cited 2020 Oct 15] ; 66( 1): 123-127.

9. Moreira Márcia Adriana Dias Meirelles, Lustosa Abdon Moreira, Dutra Fernando, Barros Eveline de Oliveira, Batista Jaqueline Brito Vidal, Duarte Marcella Costa Souto. Políticas públicas de humanização: revisão integrativa da literatura. Ciênc. saúde coletiva [Internet]. 2015 Oct [cited 2020 Oct 15] ; 20(10): 3231-3242.

10. Casate Juliana Cristina, Corrêa Adriana Katia. A humanização do cuidado na formação dos profissionais de saúde nos cursos de graduação. Rev. esc. enferm. USP [Internet]. 2012 Feb [cited 2020 Oct 15]; 46(1): 219-226.

11. Martins Catia Paranhos, Luzio Cristina Amélia. Política Humaniza SUS: ancorar um navio no espaço. Interface (Botucatu)
[Internet]. 2017 Mar [cited 2020 Oct 15]; 21( 60 ): 13-22.

12. Rosevics Letícia, et al. ProCura - a arte da vida: um projeto pela humanização na saúde. Rev. bras. educ. med., Rio de Janeiro, v. 38, n. 4, p. 486-492, 2014.

13. Pereira Alessandra Barbosa, Ferreira Neto João Leite. Processo de implantação da política nacional de humanização em hospital público. Trab. educ. saúde, Rio de Janeiro, v. 13, n. 1, p. 67-88, 2015.

14. Roza Monica Maria Raphael da, Barros Maria Elizabeth Barros de, Guedes Carla Ribeiro, Santos Filho Serafim Barbosa. A experiência de um processo de formação articulando humanização e apoio institucional no trabalho em saúde. Interface (Botucatu) [Internet]. 2014 [cited 2020 Oct 15] ; 18( Suppl 1 ): 10411052.

15. Menezes Aline Alves, Escossia, Liliana. A Residência Multiprofissional em Saúde como estratégia para a humanização: modos de intervir no cotidiano de um hospital universitário. Fractal, Rev. Psico., Rio de Janeiro, v. 30, n. 3, p. 322-329, 2018.

16. Falk Maria Lucia Rodrigues, Gonçalves Ana Valéria Furquim, Santos Denise Severo dos, Oliveira Francisco Jorge Arsego Quadros de, Fagundes Lani Brito, Ramos Marcia Ziebell et al . Depoimentos de profissionais de saúde sobre sua vivência em situação de tragédia: sob o olhar da Política Nacional de Humanização (PNH). Interface (Botucatu) [Internet]. 2014 [cited 2020 Oct 15] ; 18( Suppl 1): 1119-1124.

17. Martins Catia Paranhos, Luzio Cristina Amélia. Experimentações no apoio a partir das apostas da Política Nacional de Humanização - HumanizaSUS. Interface (Botucatu) [Internet]. 2014 [cited 2020 Oct 15] ; 18( Suppl 1): 1099-1106.

18. Morschel Aline, Barros Maria Elizabeth Barros de. Processos de trabalho na saúde pública: humanização e efetivação do Sistema Único de Saúde. Saude soc. [Internet]. 2014 Sep [cited 2020 Oct 15]; 23(3): 928-941.

19. Medeiros Lucilene Martorelli Ortiz Petin, Batista Sylvia Helena Souza da Silva. Humanização na formação e no trabalho em saúde: uma análise da literatura. Trab. educ. saúde, vol.14, n.3, Rio de Janeiro, 2016.

20. Batista Karina Barros Calife, Gonçalves Otília Simões Janeiro. Formação dos profissionais de saúde para o SUS: significado e cuidado. Saude soc. [Internet]. 2011 Dec [cited 2020 Oct 15] ; 20( 4$): 884-899$. 